\title{
DIAGNÓSTICO ETIOLÓGICO DOS TRANSTORNOS DO ESPECTRO DO AUTISMO: QUANDO E QUAIS EXAMES PEDIR?
}

Decio Brunoni

\section{Resumo}

Os Transtornos do Espectro do Autismo (TEA) são clinica e etiologicamente heterogêneos. As causas conhecidas mais frequentes são genéticas. Dezenas de síndromes cromossômicas e gênicas foram e estão sendo reconhecidas como comorbidades. No total representam em torno de 15 a $20 \%$ dos pacientes investigados. Cerca de 5\% representam causas ambientais (intercorrências perinatais). O restante dos pacientes $(80 \%)$ tem sua condição explicada por mecanismo etiológico multifatorial com interação epistática, a chamada herança complexa. A estimativa de riscos de recorrência, através do aconselhamento genético, na irmandade de indivíduos afetados varia de desprezível a $15 \%$.

Palavras chave : autismo, etiologia, exames genéticos

Brunoni, Decio. "Diagnóstico etiológico dos transtornos do espectro do autismo: quando e quais exames pedir?", in Anais do 20. Congresso Internacional Sabará de Especialidades Pediátricas 
Médico Geneticista; Livre Docente em Genética Humana e Médica. Professor Titular do Programa de Pós-Graduação em Distúrbios do Desenvolvimento do Centro de Ciências Biológicas e da Saúde da Universidade Presbiteriana Mackenzie. CAPES; FAPESP.

\title{
ETIOLOGICAL DIAGNOSIS OF AUTISM SPECTRUM DISORDERS: WHEN ORDERING AND WHAT EXAMS?
}

\begin{abstract}
Autism Spectrum Disorders (ASD) are clinically and etiologically heterogeneous. The most common known causes are genetic. Dozens of chromosomal and genetic syndromes have been and are being recognized as comorbidities. In total represent around $15-20 \%$ of the investigate patients. About 5\% represent environmental causes (perinatal in the most). The remaining patients (80\%) have a multifactorial etiology condition with epistatic interaction, the complex inheritance. The risk of recurrence in the sibs of affected individuals varies from negligible do $15 \%$.
\end{abstract}

Keywords: autism, etiology, genetics tests 


\section{Introdução}

A suposição da existência de fatores genéticos envolvidos na etiologia do autismo remonta a descrição original desse quadro clínico, em 1943, por Kanner. De fato, ao descrever os distúrbios autísticos do contato afetivo, o autor utiliza a palavra inato nas considerações etiológicas. Inato é o que está presente ao nascimento e, portanto, as causas genéticas devem ser consideradas (VOLKMAR \& PAULS, 2003).

Desde então, inúmeras evidências foram acumuladas demonstrando o papel dos genes, as quais vieram tanto da genética mendeliana clássica (recorrência na irmandade, concordância em gêmeos monozigóticos, comorbidades com síndromes monogênicas); quanto da citogenética clássica e molecular (diversas regiões cromossômicas envolvidas, microdeleções e microduplicações).

Em resumo, pode-se afirmar que o autismo e os transtornos do espectro do autismo representam o quadro neuropsiquiátrico de maior herdabilidade, em torno de 50\%. O melhor modelo etiológico que o explica é o multifatorial com interação epistática. Fatores epistáticos podem ser influencias ambientais variadas, principalmente os agravos perinatais (JESTE\&GESCHWIND, 2014).

\section{Causas Genéticas}

A investigação genética de um paciente com diagnóstico suspeito ou estabelecido de TEA é eminentemente clínico. Não há, a priori, um exame, ou uma sequência de exames, a ser solicitado, ou seja, não há triagem genética nos quadros clínicos do espectro do autismo.

A caracterização do fenótipo cognitivo comportamental por meio dos diferentes instrumentos diagnóstico é sempre importante, pois, se o diagnóstico de TEA não for bem estabelecido, haverá uma desnecessária profusão de indicações de exames genéticos. Por isso, o médico deve conhecer os fundamentos clínicos dos TEA para estabelecer o diagnóstico. De maneira geral, deve-se buscar os critérios de inclusão especificados na CID-10 e no DSM-IV para os transtornos globais do desenvolvimento, e para sistematizar a pesquisa de sinais e sintomas, podem-se utilizar escalas de triagem. 
Existem diversas escalas validadas para a população brasileira (MARTELETO\&PEDREMÔNICO; 2005; SATO et al., 2009).

Em regra todo paciente com TEA que apresentar alterações do fenótipo morfológico com ou sem deficiência intelectual deve ser investigado. Nestes pacientes encontra-se cerca de 20\% de causas genéticas. Entre elas estão síndromes muito bem conhecidas, como a Síndrome do X Frágil, a Esclerose Tuberosa até mutações de genes muito raros. A Tabela 1 apresenta as principais causas genéticas dos TEA e os exames que os identificam.

Tabela 1. Exemplos de síndromes e alterações genéticas que ocorrem em pacientes com sintomatologia de Transtornos do Espectro do Autismo

\begin{tabular}{|c|c|c|c|c|c|}
\hline $\begin{array}{l}\text { Alteração/Síndro } \\
\text { me }\end{array}$ & Quadro Clinico & $\%$ com TEA & $\begin{array}{c}\% \\
\text { entre } \\
\text { os } \\
\text { TEA }\end{array}$ & $\begin{array}{l}\text { Permit } \\
\text { e } \\
\text { suspeit } \\
\text { a } \\
\text { clínica }\end{array}$ & $\begin{array}{l}\text { Método de } \\
\text { detecção }\end{array}$ \\
\hline $\begin{array}{l}\text { Síndrome de } \\
\text { Down }\end{array}$ & típico & cerca de $10 \%$ & & $\operatorname{sim}$ & cariótipo \\
\hline $\begin{array}{l}45, X ; 47, X X Y \\
\text { polissomias } X\end{array}$ & típico & & & $\operatorname{sim}$ & cariótipo \\
\hline $\begin{array}{l}\text { Síndrome do X } \\
\text { Frágil }\end{array}$ & $\begin{array}{l}\text { variado; dismorfias DI } \\
\text { freqüente; }\end{array}$ & cerca de $30 \%$ & $\begin{array}{l}0,5- \\
1,0\end{array}$ & $\operatorname{sim}$ & teste molecular \\
\hline deleção 2q37 & $\begin{array}{l}\text { variado, DI, } \\
\text { dismorfias, }\end{array}$ & & & $\operatorname{sim}$ & cariótipo, FISH \\
\hline deleção 18q & típico, DI, dismorfias, & & & $\operatorname{sim}$ & cariótipo, FISH \\
\hline deleção 22q13.3 & $\begin{array}{l}\text { variado, DI freqüente, } \\
\text { dismorfias, }\end{array}$ & & & $\operatorname{sim}$ & cariótipo, FISH \\
\hline deleção Xp22.3 & $\begin{array}{l}\text { variado, DI } \\
\text { freqüente,dismorfias }\end{array}$ & & & $\operatorname{sim}$ & cariótipo, FISH \\
\hline $\begin{array}{l}\text { dup15q11-q13 } \\
\text { mat }\end{array}$ & $\begin{array}{l}\text { variado, DI freqüente, } \\
\text { dismorfias, }\end{array}$ & & & $\operatorname{sim}$ & cariótipo, FISH \\
\hline del dup* $16 p 11.2$ & $\begin{array}{l}\text { DI; linguagem } \\
\text { deficiente; }\end{array}$ & & & não & aCGH \\
\hline del15q13.3 & DI, convulsões; & & & não & aCGH \\
\hline $\begin{array}{l}\text { diversas del dup } \\
\text { (CNVs) }\end{array}$ & $\begin{array}{l}\text { DI; dismorfias; } \\
\text { quadros variados }\end{array}$ & $\begin{array}{c}\text { diversas } \\
\text { estimativas }\end{array}$ & $10 \%$ & não & aCGH \\
\hline
\end{tabular}




\begin{tabular}{|c|c|c|c|c|c|}
\hline $\begin{array}{l}\text { Síndrome } \\
\text { Macrocefálica } \\
\text { associada ao gene } \\
\text { PTEN }\end{array}$ & $\begin{array}{l}\text { perímetro cefálico } \\
\text { acima do + } 3 \mathrm{DP}, \mathrm{DI}\end{array}$ & & $1,00 \%$ & $\operatorname{sim}$ & teste molecular \\
\hline Síndrome de Sotos & $\begin{array}{l}\text { variado, DI freqüente, } \\
\text { leve; }\end{array}$ & & & $\operatorname{sim}$ & teste molecular \\
\hline $\begin{array}{l}\text { Esclerose } \\
\text { Tuberosa }\end{array}$ & $\begin{array}{l}\text { variado, DI freqüente; } \\
\text { crises convulsivas; }\end{array}$ & $25 \%$ & $1.0 \%$ & $\operatorname{sim}$ & teste molecular \\
\hline $\begin{array}{l}\text { Neurofibromatose } \\
\text { tipo } 1\end{array}$ & $\begin{array}{l}\text { variado, DI pouco } \\
\text { freqüente, }\end{array}$ & & & $\operatorname{sim}$ & teste molecular \\
\hline $\begin{array}{l}\text { Síndrome de } \\
\text { Joubert }\end{array}$ & $\begin{array}{l}\text { Hipo/agenesia do } \\
\text { verme cerebelar; DI }\end{array}$ & & & $\operatorname{sim}$ & teste molecular \\
\hline $\begin{array}{l}\text { Doenças } \\
\text { mitocondriais }\end{array}$ & $\begin{array}{l}\text { variado; grave; } \\
\text { histoquímica do } \\
\text { músculo alterada, }\end{array}$ & & & $\operatorname{sim}$ & teste molecular \\
\hline $\begin{array}{l}\text { Doenças } \\
\text { metabólicas }\end{array}$ & $\begin{array}{l}\text { variado; grave; } \\
\text { história de erro inato } \\
\text { do metabolismo }\end{array}$ & & & $\operatorname{sim}$ & teste bioquímico \\
\hline $\begin{array}{l}\text { Neuroliguinas } 3 \mathrm{e} \\
4\end{array}$ & DI & & $\begin{array}{r}0,5- \\
1,0 \%\end{array}$ & não & teste molecular \\
\hline SHANK3 & $\begin{array}{l}\text { DI; } \\
\text { comprometimentosoc } \\
\text { ial e de linguagem } \\
\text { intensos }\end{array}$ & & & não & $\begin{array}{c}\text { teste molecular, } \\
\text { aCGH }\end{array}$ \\
\hline Neurexina 1 & $\begin{array}{l}\text { DI; convulsões, } \\
\text { dismorfias, }\end{array}$ & & $\begin{array}{l}\text { meno } \\
\text { s de } \\
0,5 \%\end{array}$ & não & teste molecular \\
\hline $\mathrm{MeCP} 2$ & $\begin{array}{l}\text { Meninas com TEA e } \\
\text { DI, sem clínica de } \\
\text { Síndrome de Rett, } \\
\text { tem mutação neste } \\
\text { gene em cerca de } \\
1,5 \% \text { dos casos. }\end{array}$ & & & $\operatorname{sim}$ & teste molecular \\
\hline $\begin{array}{l}\text { Diversas } \\
\text { Síndromes }\end{array}$ & $\begin{array}{l}\text { Cornelia de Lange, } \\
\text { Angelman, Williams, } \\
\text { San Filippo, Moebius } \\
\text { apresentam TEA em \% } \\
\text { mal definida }\end{array}$ & & & $\operatorname{sim}$ & clinico \\
\hline
\end{tabular}

* microdeleções/duplicações ; FISH: fluorescence in sity hybridization; aCGH: array comparative genemoe hybridization DI: deficiência intelectual; del dup: duplicações e deleções ; CNVs: copy number variations \%com/entre os TEA em branco : sem estimativa confiável 
Não considerando as síndromes morfológicas clássicas como Síndrome de Down, síndrome de Prader-Willi ou Síndrome de Angelman, as quais podem se apresentar em comorbidade com os TEA, dificilmente existe um marcador morfológico que levante uma suspeita diagnóstica para uma mutação específica. Um possível exemplo é a macrocefalia associada às mutações do gene PTEN (BETANCUR, 2011; JESTE\&GESCHWIND, 2014).

\section{Causas Ambientais}

Há um grande número de teorias quanto a possíveis causas ambientais. Os eventos pré e peri-natais já foram relatados como apresentando alta incidência na história das crianças com autismo quando comparado com seus irmãos e com controles normais. Desde quadros de asfixia, de infecções, de agentes teratogênicos (bebidas alcoólicas ou abortivos como o misoprostol) até stress materno na gestação têm sido relatados. Estes diversos agravos ao embrião e/ou feto que apresenta vulnerabilidade genética ao transtorno explicaria o mecanismo causal.

Das inúmeras causas ambientais relatadas parece ser mais consistente a prematuridade e o baixo peso ao nascer (TORDJMAN et al., 2014).

Em conclusão podemos dizer que a identificação de fatores genéticos e ambientais possibilitam o esclarecimento de cerca de 20 a 25\% dos pacientes com diagnóstico de TEA. Estes pacientes com causa definida terão as condutas clinicas e de aconselhamento genético de acordo com a causa: os riscos de recorrência podem variar de insignificantes como nos casos esporádicos nos quais a mutação genética ocorreu de novo, ou seja, pela primeira vez até riscos consideráveis de 50\% (translocações cromossômicas herdadas; mutações dominantes herdadas ou 25\% síndromes com modelo autossômico recessivo. Nestye t'pico do aconselhamento genético, lembrar com particular cuidado da síndrome do X Frágil (FRAXA) na qual casos esporádicos tem risco, a priori, de 30\% de trem sido herdados da mãe. Sempre será necessário a investigação da condição materna de heterozigota.

Uma vez esgotadas as possíveis causas identificáveis os pacientes com TEA são interpretados como decorrentes de herança multifatorial. Neste modelo, variantes genômicas de vulnerabilidade ao transtorno, associadas a causas ambientais perinatais, seriam a causa do TEA. No momento, este modelo explica a grande maioria dos casos (cerca de 80\%). O aconselhamento genético aqui se dá em função do modelo 
multifatorial: tanto maior quanto maior for o grau de parentesco com o afetado. Para irmãos este risco varia de 10 a 15\% (SANDIN et al., 2014).

\section{Quando e quais exames pedir}

A investigação etiológica dos pacientes com TEA pode ser orientada segundo o fluxo mostrado na Figura 1.

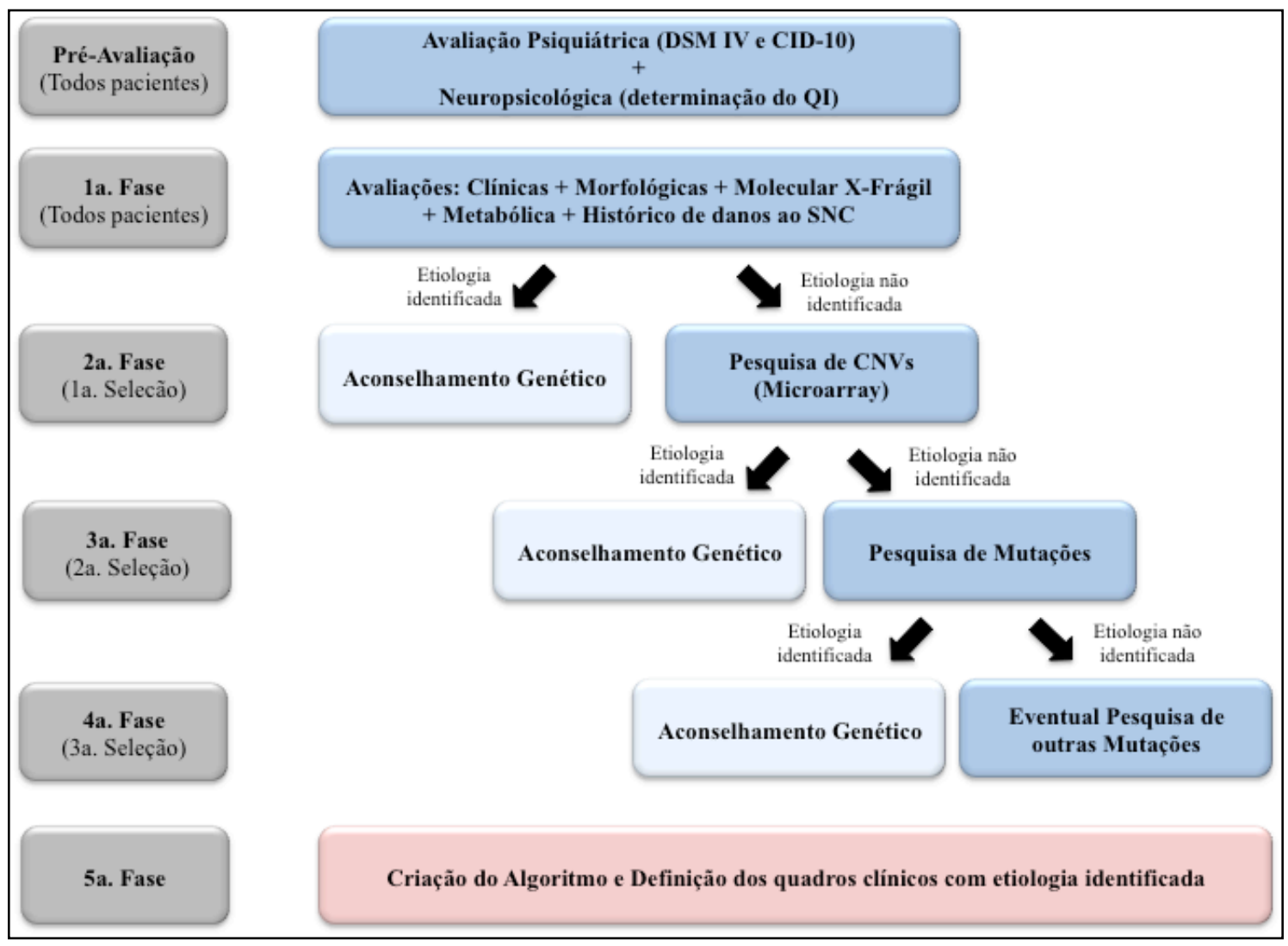

Figura 1. Roteiro de investigação diagnóstica em indivíduos com TEA para pesquisas causas genéticas e ambientais

A Figura 1 enfatiza o principal aspecto na investigação etiológica dos TEA: a garantia de que o diagnóstico do transtorno esteja correta (fase de pré-avaliação). Dai em diante a quantidade de exames a serem solicitados dependem da disponibilidade de cada sistema de saúde. No Brasil SUS e saúde complementar separam os pacientes radicalmente. No SUS garantir exame de cariótipo e do X Frágil é o desafio atual. Na saúde suplementar a separação dos pacientes é feita pelo tipo de plano que a família possui. Existem planos que dificultam até a realização do mais elementar dos exames genéticos, o cariótipo com bandas G (plenamente garantido pelo Agência Nacional de 
Saúde). Diversos planos da saúde complementar tem cobertos custos de exames genômicos mais dispendiosos como o sequenciamento gênico ou o sequenciamento exônico. Para informar-se melhor sobre esta situação, devemos incentivar nossos pacientes a procurarem informações como as fornecidas no site da Sociedade Brasileira de Genética Médica (http://www.sbgm.org.br/orientacoes.asp).

\section{Referências}

BETANCUR C. Etiological heterogeneity in autism spectrum disorders: more than 100 genetic and genomic disorders and still counting. Brain Research 2011; 1380:42-77.

JESTE, S.S., GESCHWIND, D., H. Disentangling the heterogeneity of autism spectrum disorder through genetic findings. Nat.Rev.Neurol. 2014; 10(2):74-81.

MARTELETO, M. R. F; PEDREMÔNICO, M. R. M. Validade do Inventário de Comportamentos Autísticos (ICA): Estudo preliminar. Revista Brasileira de Psiquiatria, v.27, n.4, p.295-30, 2005.

TORDJMAN, S., SOMOGYI, E., COULON N. et al. Gene x environmental interactions in autism spectrum disorders: role of epigenetic mechanisms. Frontiers in Psychiatry, 2014:aricle 53; doi:10.3389/fpsyt.2014.00053

SANDIN, S., LICHTENSTEIN, P., KUJA-HALKOLA, R. et al. The familial risk of autism. JAMA. 2014; 311(17):1770-1777.

SATO, F.B.; PAULA, C.S.; LOWENTHAL, R. et al. Instrumento para rastreamento dos casos de transtorno invasivo do desenvolvimento - estudo preliminar de validação. Rev Bras Psiquiatr. 2009;31(1):30-3.

VOLKMAR FR, PAULS D. Autism. Lancet 2003; 362:1133-41. 